\title{
A GEOGRAPHIC ANALYSIS OF OPTIMAL SIGNAGE LOCATION SELECTION IN SCENIC AREA
}

\author{
Ling Ruan $^{\text {a,b,c }}$, Ying Long ${ }^{\text {a,b,c }}$, Ling Zhang ${ }^{a, b, c}$, Xiao Ling $\mathrm{Wu}^{\mathrm{a}, \mathrm{b}, \mathrm{c}}$ \\ ${ }^{\text {a }}$ School of Geography Science, Nanjing Normal University, Nanjing 210023, China \\ ${ }^{\mathrm{b}}$ Key Laboratory of Virtual Geographic Environment, Ministry of Education, Nanjing Normal \\ University, Nanjing 210023, China \\ ${ }^{c}$ Jiangsu Center for Collaborative Innovation in Geographical Information Resource Development and \\ Application, Nanjing 210023, China
}

Commission II, WG II/7

KEY WORDS: Signage, Signage Location, Scenic Areas, Location Selection

\begin{abstract}
:
As an important part of the scenic area infrastructure services, signage guiding system plays an indispensable role in guiding the way and improving the quality of tourism experience. This paper proposes an optimal method in signage location selection and direction content design in a scenic area based on geographic analysis. The object of the research is to provide a best solution to arrange limited guiding boards in a tourism area to show ways arriving at any scenic spot from any entrance. There are four steps to achieve the research object. First, the spatial distribution of the junction of the scenic road, the passageway and the scenic spots is analyzed. Then, the count of scenic roads intersection on the shortest path between all entrances and all scenic spots is calculated. Next, combing with the grade of the scenic road and scenic spots, the importance of each road intersection is estimated quantitatively. Finally, according to the importance of all road intersections, the most suitable layout locations of signage guiding boards can be provided. In addition, the method is applied in the Ming Tomb scenic area in China and the result is compared with the existing signage guiding space layout.
\end{abstract}

\section{INTRODUCATION}

The scenic signage guiding system is refer to the space and information environment, through different carriers, to comprehensive solution to the information transmission, identification, image transfer and other difficulties to help foreign tourists to obtain the required information system in the fastest time. As the important part of the tourism infrastructure, the scenic signage guiding system help tourists get the correct spatial direction and nearby environment information, ensure the activities of tourists in normally order. There are many problems in the scenic signage guiding system about the location and direction content in many scenic areas in china which is one of the countries in the world in which the tourism industry grows very fast currently. There is no unified planning of the layout of the scenic signage in order to cause that the space layout of the signage is not reasonable to waste of resources and so on. In the process of design the scenic signage, just from the angle of scenic management, without systematic theoretical guidance, and ignore the tourists' travel behaviour which can impact the tourists' travel experiences.

Planning and design of the scenic signage guiding system should be Meet the needs of the tourists walking rules and resource saving. The direction content, location and number of the signage need be fully optimized in scenic area. Tilden (1957) has pointed out that the number of the signage does not require too many very early, which not only caused visual fatigue for tourists, but also increase the cost of construction of scenic area. Good (1999) thought the insufficient number of signage could not play the role of guiding effect, and may lead to that the interruption of information, way finding difficulties and lost in tourists. Therefore, the study of the optimal location selection and direction content design method in the scenic signage has very important application value to improve the tourists experience and reduce the construction cost of scenic area. In recent years, the domestic and foreign scholars have done a lot of research work on the space layout of the scenic signage guiding guidance system. Xia (1999) put forward planning guide with the space layout by the angle of the cognitive psychology of tourist attractions. Findlay (2004) analysis the influence of different spatial layout mode of signage guide board on tourists. Edwards (2013) exploited the analysis of its spatial behavior characteristics by GPS track of tourists that study the spatial distribution of the guide plate. Zhao (2010) put forward the method of according to the number of tourists, the importance of scenic spots and the geographic feature of the scenic road network to construct the scenic signage guiding system. However, among all these researches, the current research focuses on the evaluation of the space layout of the signage. In terms of spatial layout and design methods of signage, there are far more qualitative analysis studies than quantitative ones.

For this reason, this article presents the new method on spatial characteristics of the scenic road network, and use GIS spatial analysis method, put forward the optimal location and content design method of the scenic signage guiding system. According to spatial behaviour rule of tourists, this paper simulated the tourist routes in scenic area, calculated of the importance of each junction node in road network, statistic the number and information of destination scenic spots in each junction node which the simulated the tourist routes through, and then automatically generate the optimal number, the layout location and direction content of the signage in scenic area

\section{METHOD}

\subsection{Basic thinking}

The basic thinking of the method is shown in Figure 1. From the point of view of the temporal and spatial distribution 
regulation of tourists travel in scenic area, firstly, this paper used the road network data, scenic spots data (include location, name and grade), passageway data (include location, name and grade), extract road junction node according to the spatial topological structure of road network data, simulate tourists route by generated the shortest path between scenic spot and scenic spot and the shortest path between scenic spot and passageway, then statistic the spatial relation between the junction node and tourists route to study the optimal number, location selection and direction content design problem in scenic area. In this paper, the research of the location selection about the signage is default located at the junction node of the road, and the direction content of the signage is the information of the scenic spot.

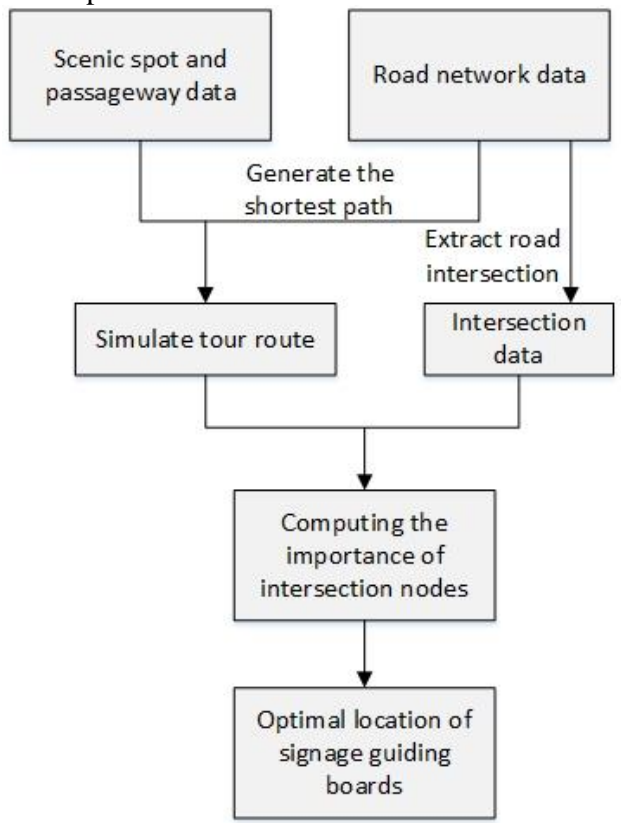

Figure.1.The process of basic thinking

\subsection{The simulation of tourists route}

The location selection of signage in scenic area should put tourist activities first and fully meet their tour needs (Moosavi, 2011). Kellne analysed daily travel activities regularly of tourists by GPS trajectory data of tourists, and we discovered that its tour route mainly focus on the route between passageway and scenic spot and the route between scenic spot and scenic spot. That is difficult in acquisition of GPS trajectory data of tourists in different scenic spots. Therefore this paper builds the shortest path between passageway to scenic spot and shortest path between scenic spot and scenic spot to simulate tour route of tourists according to scenic spot data, passageway and road network data of scenic spot, as shown in figure 2 . The method to study the location selection of signage by simulating tour route of tourists is feasible.

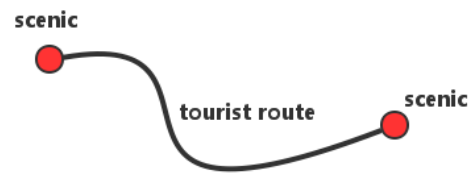

(a) The shortest path between scenic spot and scenic spot

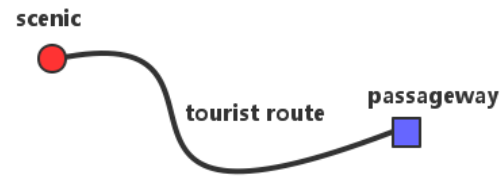

(b) The shortest path between passageway and scenic spot Figure.2.Simulate the tour route of tourists

In this paper, Scenic spot data is $S=\left\{S_{1}, S_{2}, \ldots, S_{n}\right\}$, where $S_{n}=\left\{x_{n}, y_{n}, d_{n}\right\}, x_{n}$ is treated as the longitude of scenic spot, $y_{n}$ is treated as the latitude of scenic spot, $d_{n}$ is treated as the grade of scenic spot which comes from the industry-standard of Quality grade division and evaluation of scenic spot in china (GB/T17775-2003). Passageway data is $E=\left\{E_{1}, E_{2}, \ldots, E_{m}\right\}$, where $E_{m}=\left\{x_{m}, y_{m}, d_{m}\right\}, x_{m}$ is treated as the longitude of passageway, $y_{m}$ is treated as the latitude of passageway, and $d_{m}$ is treated as quantity level of passageway tourists flow.

Based on the existing road network data of scenic area, The directed shortest path between scenic spot data and passageway data built, which the number of that is $m * n$. And the directed shortest path between scenic spot and scenic spot built, which the number of that is $n^{2}$. At last, there are $n^{2}+m n$ simulated tourists routes in this paper, That is Route $=$ $\left\{R_{1}, R_{2}, \ldots, R_{\left(n^{2}+m n\right)}\right\}$.

\subsection{Computing the importance of junction node}

The signage is generally located in the important junction road node in the scenic area, but the importance of the junction node is determined by the management person, which lack of scientific basis. This section could quantitative calculate the value of the importance of each junction node through the simulation of tourists routes. Firstly, there are $a$ road junction node extract by the spatial topological structure of road network data as the optional location of signage in this paper, namely Cross $=\left\{C_{1}, C_{2}, \ldots, C_{a}\right\}$, where $C_{a}=\left\{x_{a}, y_{a}\right\}, x_{a}$ is treated as the longitude of junction node, $y_{a}$ is treated as the latitude of junction node.

Loop through the spatial relationships among all junction nodes (Cross) and tourists routes (Route), when junction nodes $C_{a}$ in the tourists route $R_{\left(n^{2}+m n\right)}$ or their distance in a certain spatial threshold value, then the tourist route is identified that through the junction node, as shown in figure 3 .

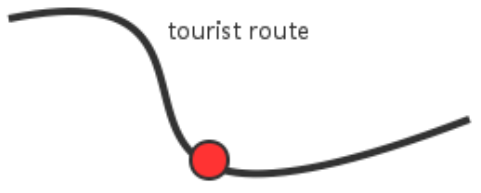

junction node

(a) The junction node $C_{a}$ in the tourist route 


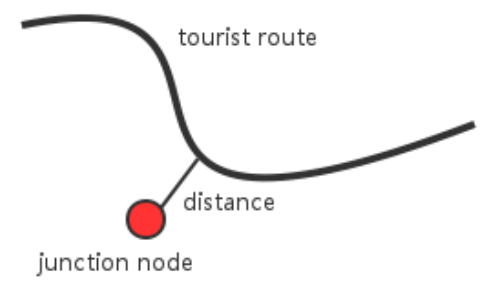

(b) The distance between junction node and tourist route in a certain spatial threshold value

Figure 3 Spatial relationships between intersection node and tourist route

Then the grade of start scenic spot, the end scenic spot and the passageway of tourist route through the junction node were recorded, ultimately $T_{a}$ the value of the importance of junction node is obtained by summation of the following formula.

$$
T_{a}=\sum_{k=1}^{n^{2}+m n} \frac{\left(d_{k, s}+d_{k, e}\right)}{2}
$$

Where $d_{k, S}$ is treated as the grade of start scenic spot or passageway in tourist route $k$, and $d_{k, e}$ is treated as the grade of destination scenic spot or passageway in tourist route $k$.

Besides, the destination scenic spot $S_{\text {end, }, a}$, its frequency $T_{s, a}$ and its direction $\beta$ need to be counted where each tourist route through the junction node $C_{a}$.

Finally, $T_{a}$ the importance of junction nodes which were quantitative computed would be sorted descending, we could obtained the value of the importance in each junction nodes $T_{\text {Cross }}=\left\{T_{1}, T_{2}, \ldots, T_{a}\right\}$, where $T_{a}$ contain the information of junction nodes $C_{a}$, the destination scenic spot $S_{\text {end,a }}$ and its frequency $T_{s, a}$ and its direction $\beta$ which in the tourists route. Those data were treated as basis of optimal location selection of signage.

\subsection{Optimal location selection of signage}

In the condition that constraining the number of signage $M$, and $M<a$, the junction nodes were selected in turn according to the descending importance order of junction nodes $T_{\text {Cross }}=$ $\left\{T_{1}, T_{2}, \ldots, T_{a}\right\}$, and the location result of signage is $T_{M}=$ $\left\{T_{1}, T_{2}, \ldots, T_{M}\right\}$.

Facing with the optimal location selection of signage in scenic area, the method built the function of the optimal solution by considered the importance of the signage and the construction cost set as follows

$$
F=\frac{\sum_{i=0}^{a} T_{i}}{\sqrt{i}}
$$

Where $i$ represents the number of the signage, $T_{i}=$ $\sum_{k=1}^{n^{2}+m n} \frac{\left(d_{k, s}+d_{k, e}\right)}{2}$. As a convergence function, when $i=M$, the objective function $F_{\max }$ achieved the maximum value. According to the descending value of importance in each junction nodes $T_{\text {Cross }}=\left\{T_{1}, T_{2}, \ldots, T_{a}\right\}$, the optimal solution of the signage in scenic area is $T_{M}=\left\{T_{1}, T_{2}, \ldots, T_{M}\right\}$, where $T_{i}$ contain the location information of junction nodes and $M$ is the optimal number.

\subsection{Content design of signage}

After achieve the optimal selection number and the location of the signage in scenic area, the direction content of signage is most concerned for tourist. This paper can automatically generate the direction content of the signage in each selected junction node, which according to the destination scenic spot and frequency data.

We assume that a signage should display $N$ scenic direction information. When the optimal location result of the signage in scenic area is $T_{M}=\left\{T_{1}, T_{2}, \ldots, T_{M}\right\}$, loop through the descending order of $T_{M}$ and deal with it one by one according to the following steps.

First of all, we sort the destination scenic data $T_{M}$ in descending order according to the direction $\beta$ and frequency $T_{s, a}$ to get the frequency decreasing scenic data $S_{\text {end,a }}=$ $\left\{S_{1}, S_{2}, \ldots, S_{i}\right\}$ in each direction.

When the number of crossing in junction nodes dir is less than $N$, firstly, take out and record the highest frequency scenic spot information $T_{s, a, \max }$ in all directions. Secondly, eliminate the highest frequency scenic spot data in all directions and assign $N-$ dir directing information, then select he highest frequency scenic spot information in all directions. According to the frequency descending sort, select the $N$-dirscenic spot information in order.

When the number of crossing in junction nodes dir is greater than or equal to $N$, firstly, take out and record the highest frequency scenic spot information $T_{s, a, \max }$ in all directions, then sort in descending order and select $N$ scenic spot information.

This method could get the most hot scenic spot that the tourist want to go according to the number of the destination scenic spot in tourist routes in each junction node and the direction content of the junction node which reflecting the humanization of tourism experience, which based on simulated tourists routes.

\section{TEST AND ANALYSIS}

\subsection{Test area and data preparation}

In order to verify the effectiveness of the method described in this paper, we select the Ming Tomb scenic area as the experimental area which is China 5A grade scenic area. Ming Tomb scenic area is located in Nanjing City, China, covers an area of 1 million 700 thousand square meters, and was included in the world heritage list. There are 39 scenic spots, 6 passageways (entrances and exits) and 47 emplaced signage and road network data collected in scenic area, and the emplaced signage data contain coordinate position and content, as shown in Figure 4. 139 junction nodes were extracted in road network. In 47 signage, there are 41 signage laid in the 29 junction nodes, other 6 signage laid in the middle section of the route. Then, the test results are analysed from the location selection and direction content of signage in Ming Tomb scenic area. 


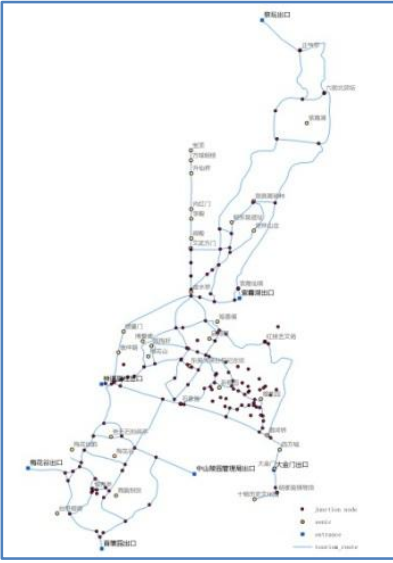

(a) The collected basic data in Ming Tomb scenic area

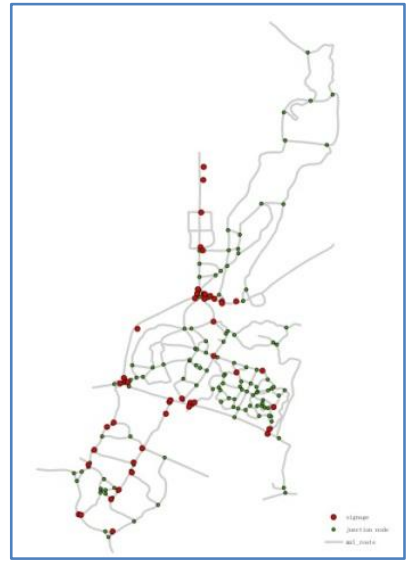

(b) The emplaced signage in Ming Tomb scenic area

\subsection{The Analysis of optimal selection result}

According to the test data collected, the first step is to simulate the tourist routes. There are 2116 simulation tourist routes in Ming Tomb scenic area which by generated the shortest path between scenic spot and scenic spot and the shortest path between scenic spot and passageway, as shown in Figure 5.

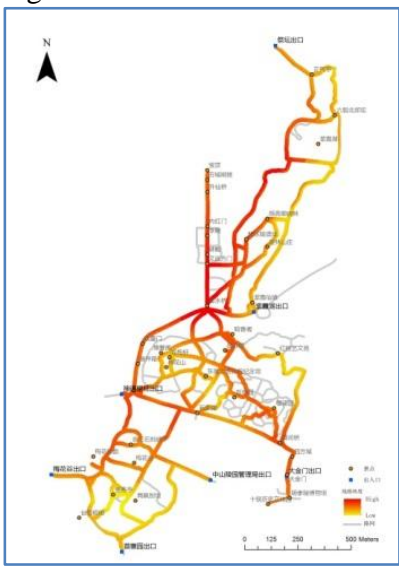

(a) The simulation of tourists route

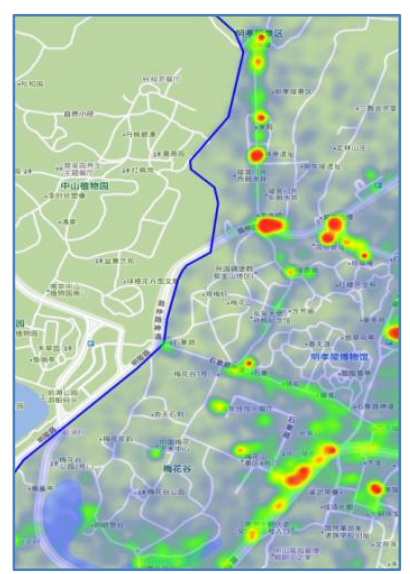

b Actual scenic tourists heat map
Figure.5.The compare between the simulation routes and the actual tourists heat-map

As shown in Figure 5(a), this paper analysis the hot spot by discrete simulation of the tourist routes, and compared with the tourists heat-map from Baidu Map (China's largest online map service providers, real-time access to mobile data terminals display traffic information, time:2016-04-03 12h). The hot area in tourist route is basically same with the heap-map in Figure 5 (b), so this is feasible through the simulation of the tourist routes to represent the common tourist tour line.

After classification of the grade in scenic spots and passageway, we set the distance threshold between the junction node and the tourist route is 5 meters, calculate the value of the importance in each junction node by this paper method, the result as shown in Figure 6, Among them, the importance of zero junction node is not on any tourist routes.

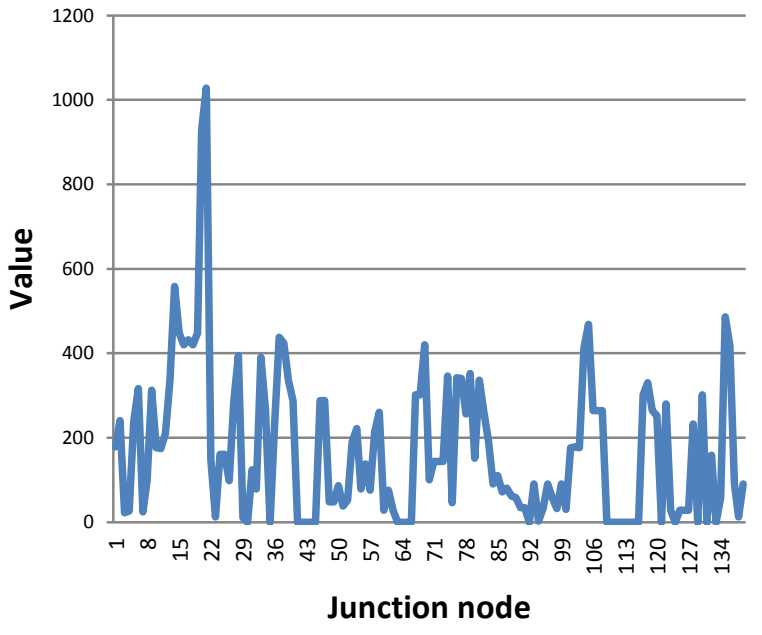

Figure.6.The value of the importance in each junction node

The higher importance of several junction nodes concentrated in the "Golden Bridge" area, which is located nearby the most important entrance and connect to other scenic spots and is the central region and the entire area of the traffic arteries. Therefore, the result of the importance in each junction nodes calculated is in accord with the actual situation.

According to the optimal location selection method in the descending importance order of junction nodes, we get the optimal distribution of the number of signage, as shown in Figure 7 . When the number is 56 , the maximum value is obtained.

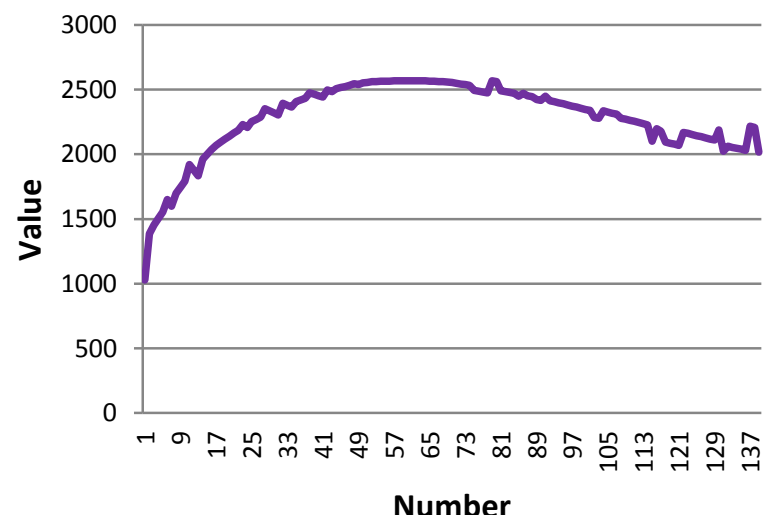

Figure.7. The optimal distribution of the number of signage

The result about the optimal selected location and the emplaced signage location compared shown in Figure.8. There are 29 junction node have emplaced signage, and the number is 53 is this paper. 20 are in agreement with the current location, and the anastomosis rate is $68.9 \%$. In "export to the altar", "old villa" and "Zixia Lake" region in The Ming Tomb scenic area, there has no signage, although the region is relatively remote, it should be deployed, used to guide tourists. 


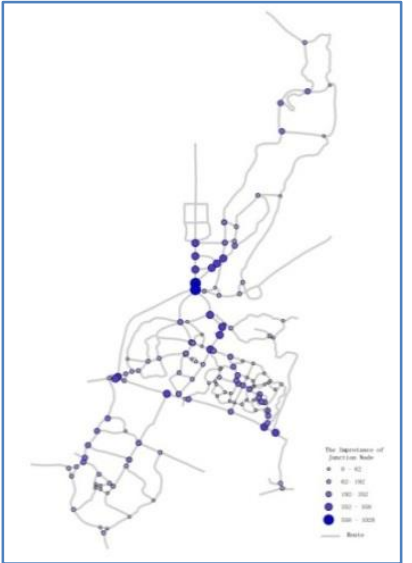

(a) The junction node importance distribution

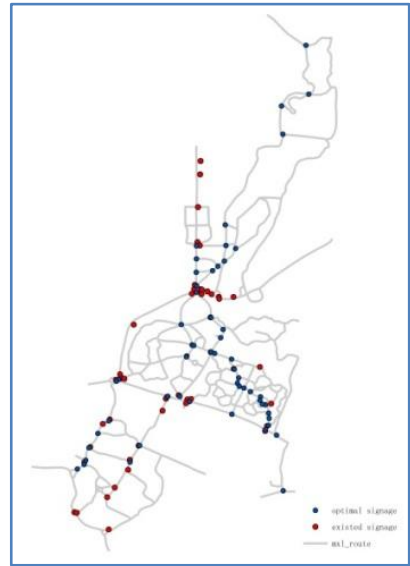

(b) The compare with optimal and actual
Figure.8.The result about the optimal location selection method

\subsection{The Analysis of direction content design}

In the actual layout of the direction content in signage, in addition to scenic spots, some infrastructure such as the bathroom and the entrance also in direction content, but the experiment of this paper only studies the information of scenic spot. In this test, we set up 5 direction content about scenic spots, and the junction node is consistent with the area of 20 which in agreement with the current location. The average accuracy of the direction content design compared with current design is $48 \%$ based the method in this paper, as shown in Figure.9. Although the average accuracy is not high, but this method is based on the behaviour of tourists, refer to the most want to go to the scenic spot at the junction node.

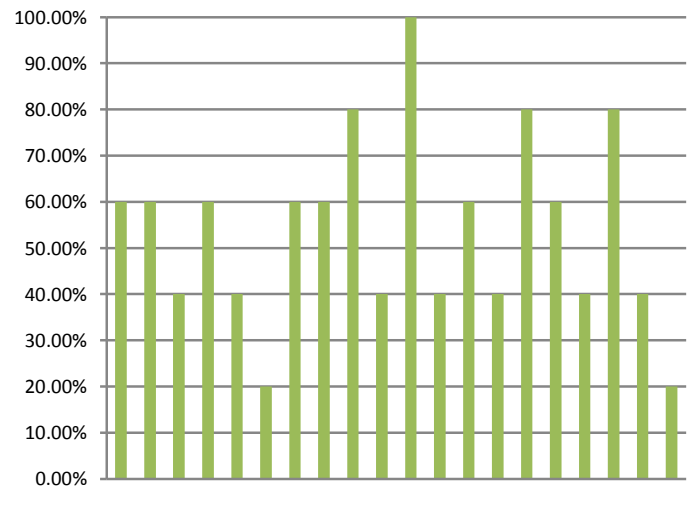

$\begin{array}{llllllllll}1 & 3 & 5 & 7 & 9 & 11 & 13 & 15 & 17 & 19\end{array}$

Figure.9.The accuracy about the direction content in each junction node compared with actual

\section{CONCLUSION}

This paper is aimed at the problem of optimal signage location selection in scenic area, based on the data of the scenic spot, the passageway and the road network, simulated tourist routes, put forward a new method about the optimal location selection and direction content design by statistic spatial relationship, quantitative calculate of the optimal layout location and direction content, test at the Ming Tomb scenic area which located in Nanjing City, China. Although there are some differences between the experimental results and the actual location and content of signage, the method is based on the tourist route, and simulates the behaviour of the tourists, In addition, there is no better evaluation criterion to determine the pros and cons of the layout program. Therefore, this paper has an important reference value for the location selection of signage in scenic area which based on spatial analysis and the theory of tourist behaviour.

The location analysis of signage in scenic area involves many aspects of the service management of the scenic. Next, this paper will get further and deep study of the no-junction nodes location selection, expand the direction content to other services and establish a systematic evaluation mechanism of signage, construct t signage guiding system to meet the needs of the tourists from the point of view of spatial analysis.

\section{ACKNOWLEDGEMENTS}

Supported by National Natural Science Foundation of China (Grant No.41571382) ;

Supported by National Natural Science Foundation of China (Grant No. 41301144) ;

Supported by the Natural Science Foundation of the Jiangsu Higher Education Institutions of China(Grant No. 15KJB170006 ).

\section{REFERENCES}

Tilden, F., 1957. Interpreting Our Herirage. University of North Carolina Press, pp. 145-146

Good, A., 1999. Park and recreation structures. Princeton Architectural Press, pp.276-276.

Xia J C, Arrowsmith C, Jackson M, 1999. Park and recreation structures. Princeton Architectural Press, pp.276-276.

Findlay C, Southwell K.I just followed my nose': understanding visitor wayfinding and information needs at forest recreation sites. Managing Leisure, 2004, 9(4): 227-240.

Edwards D, Griffin T. Understanding tourists' spatial behaviour: GPS tracking as an aid to sustainable destination management. Journal of Sustainable Tourism, 2013, 21(4): 580-595.

Zhao D D, Qin A C, Jia H N, et al. Design of Tourism Signage with Visitor Visual Angle in Xibaipo[J]. Journal of Northwest Forestry University, 2010

Moosavi R. The Study of Tourism Signage Understandability towards Travelers Satisfaction[C]// International Conference on Performing Arts as Creative Industries in Asia. 2011.

Kellner L, Egger R. Tracking Tourist Spatial-Temporal Behavior in Urban Places, A Methodological Overview and GPS Case Study[C]// Enter. 2016. 